\title{
Almócita, ecomuseo y agroecología para ganar a la despoblación
}

Sergio Pineda Iglesias | promotor cultural del Ayuntamiento de Almócita y agente de innovación local del centro Guadalinfo

URL de la contribución <www.iaph.es/revistaph/index.php/revistaph/article/view/4442>

\section{RESUMEN}

El Ayuntamiento de Almócita, para frenar el problema del despoblamiento rural, ha cambiado la dinámica de gestión hacia un modelo de democracia participativa con vecinos y asociaciones, para conseguir la transformación de nuestra sociedad global trabajando los valores desde lo local. En este contexto surge el proyecto de Almócita en Transición. La base es el empoderamiento de la ciudadanía, su amor por la cultura y la recuperación de las tradiciones, para conocer e involucrar así al tejido social y dar a conocer/conservar el patrimonio en todas sus variantes (material e inmaterial), usándolo, además, como seña de identidad. La puesta en valor del patrimonio en todas sus variantes, el embellecimiento municipal a través del arte, la poesía y los murales colaborativos, junto con las acciones de agroecología y permacultura, están siendo los pilares del proyecto global y del ecomuseo/pueblo

\section{Palabras clave}

Agroecología | Almócita (Almería) | Almócita en Transición | Despoblamiento | Empoderamiento ciudadano | Participación ciudadana | Resiliencia | 


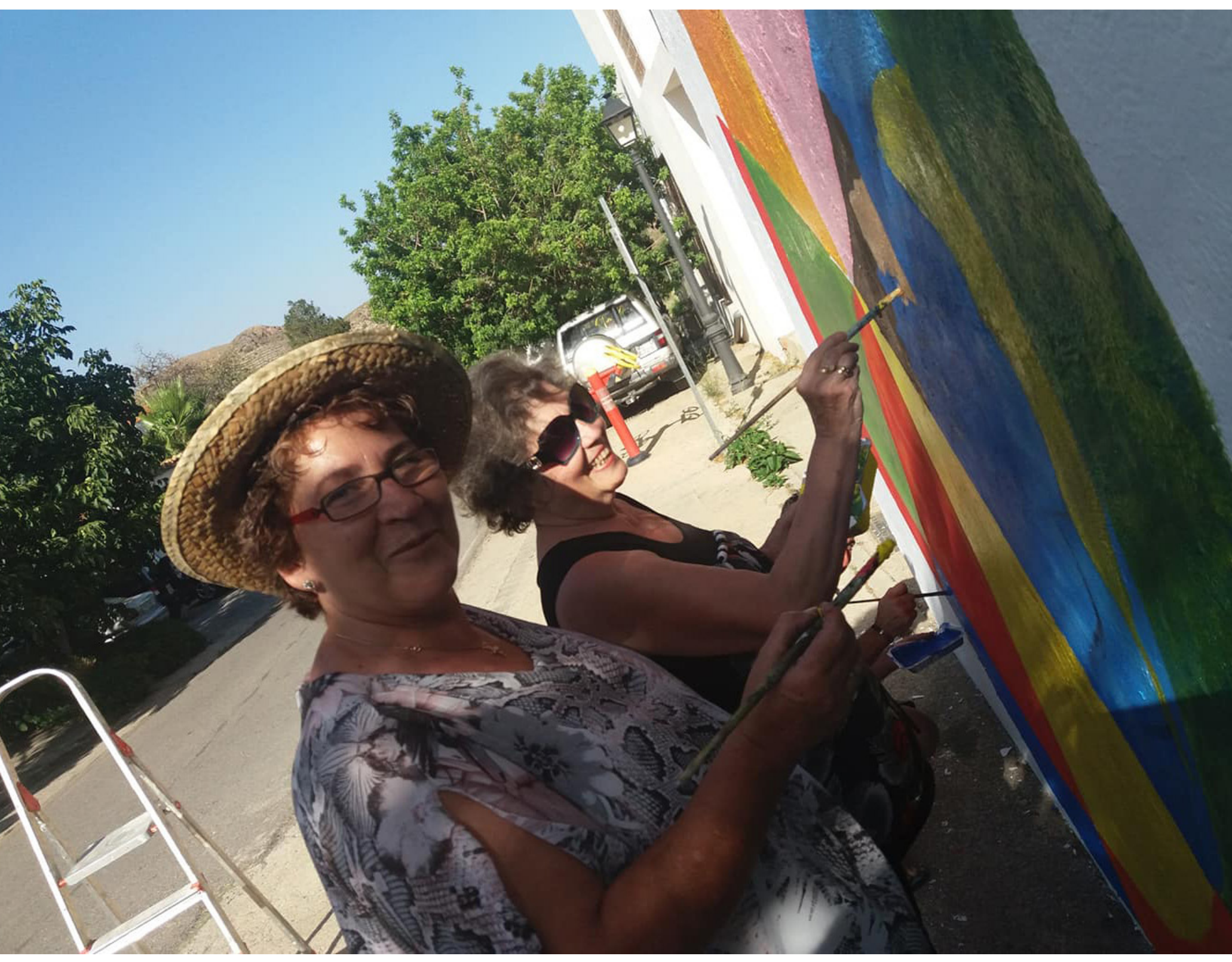

Taller de pintura creando el mural colaborativo guiado del juego del amor | foto Sergio Pineda Iglesias 


\section{ALMÓCITA EN TRANSICIÓN, BÚSQUEDA DEL EMPODERAMIENTO DE LA CIUDADANÍA}

Almócita, pequeño municipio de 174 habitantes de la Alpujarra de Almería que ha perdido más de la mitad de la población en los últimos cincuenta años, se enfrenta a "la problemática de la despoblación rural, una de las mayores lacras que sufren los territorios rurales de toda España" (VV. AA., 2014), debido a la falta de posibilidades laborales, al abandono de las producciones agrícolas tradicionales, que no son competitivas hoy día, miedo a la pérdida de los servicios públicos básicos, falta de apoyo económico directo, mala imagen social que se vende de la vida en los pueblos y al exceso de interés mostrado por el Estado en el desarrollo de las ciudades como único foco de vida posible, sin tener en cuenta que, según Romero Renau (en GANTES, 2018), "desde pequeños se nos machaca con que lo mejor está en la ciudad y luego las ciudades están llenas de parados juveniles", con un cambio de estrategia municipal, creando un proyecto municipal global participativo basado en la sostenibilidad ambiental, la democracia participativa vecinal, el desarrollo de la democratización de la cultura (ecomuseo al aire libre) y la agroecología, como bases para la conservación poblacional, la de su patrimonio, el cambio en la relación habitante-institución, el uso de la consciencia colectiva y del amor colectivo para conseguir la pervivencia como pueblo, en el futuro.

1

<http://www.reddetransicion.org/municipios-en-transicion/> [Consulta_30/09/2019].

2

Asociación de Mujeres Fuente de los Naranjos, Asociación Cultural Los Tres Caños, Asociación de la Iglesia San Blas, Asociación Cultural el Árbol de la Vida, Asociación de Jóvenes al cubo con futuro, Asociación Trotamundos Animado, Asociación Casa Farfana y Club Depostivo Almócita Activa.

3

Como el caso de Ecologistas en Acción, Asociación Cetha, Red Terrae y la Asociación Española Contra la Despoblación.

4

Coordinadora, energía sostenible, participación, patrimonio y sistema agroalimentario local.
Para la gestión y organización global de este proyecto municipal, Almócita está hermanada con el nuevo movimiento "Municipios en Transición"1, con el objetivo de conseguir un municipio en proceso de cambio hacia una vida más sostenible, justa y feliz para sus habitantes. Partiendo de la posibilidad de crear otra realidad local al mundo globalizado, donde resiliencia, el uso ético de nuestros recursos, el comercio local, la puesta en valor de nuestra identidad, la preeminencia de la colectividad, la unión arte-cultura-sostenibilidad y la relación de amor con el territorio-paisaje que hemos heredado, son las herramientas para desafiar los problemas del despoblamiento y abandono rural, el pico del petróleo, el cambio climático y las crisis económicas (ALBELDA; PARREÑO; MARRERO, 2018.)

Almócita, tras años de asambleas vecinales y actividades colaborativas donde el motor de impulso es el Ayuntamiento en colaboración con el vecindario, el Centro Guadalinfo, las asociaciones locales ${ }^{2}$ y otras entidades que colaboran puntualmente en actividades ${ }^{3}$, crea a nivel organizativo "Almócita en Transición", dividida en diferentes grupos de trabajos ${ }^{4}$, para realizar propuestas, debates y espacios de reflexión comunitaria, con los diferentes proyectos que están en marcha y otros que se comenzarán.

Nos adentraremos en uno de los proyectos clave y que ha servido de factor de ignición para la creación de esta propuesta global de Almócita, que es el proyecto de Ecomuseo. 


\section{APROXIMACIÓN AL CONCEPTO DE ECOMUSEO DE ALMÓCITA}

Nuestra idea de ecomuseo global abierto proviene de la interacción y mezcla de los siguientes conceptos. Por un lado, el extraído de la Red Europea de los Ecomuseos, que expone que: "un ecomuseo es un proceso dinámico con el cual las comunidades preservan, interpretan y valoran su patrimonio para el desarrollo sostenible. Un ecomuseo se funda en un acuerdo con la comunidad." (Red Europea de los Ecomuseos). Por su lado, el Natural History Committee del ICOM (organización no gubernamental, que mantiene una relación formal con la UNESCO y tiene estatus de órgano consultivo del Consejo Económico y Social de las Naciones Unidas) ha elaborado una propia definición de ecomuseo: "El ecomuseo es una institución que gestiona, estudia y valora -con finalidades científicas, educativas y, en general, culturales- el patrimonio general de una comunidad específica, incluido el ambiente natural y cultural del medio. De este modo, el ecomuseo es un vehículo para la participación cívica en la proyección y en el desarrollo colectivo. Con este fin, el ecomuseo se sirve de todos los instrumentos y los métodos a su disposición con el fin de permitir al público comprender, juzgar y gestionar-de forma responsable y libre- los problemas con los que debe enfrentarse. En esencia, el ecomuseo utiliza el lenguaje del resto, la realidad de la vida cotidiana y de las situaciones concretas con el fin de alcanzar los cambios deseados." (Natural History Committee del ICOM).

En definitiva, nuestro ecomuseo está pensado desde la idea de crear un instrumento de gestión del patrimonio con una perspectiva territorial, adaptado a las actuales demandas de uso social del mismo y del desarrollo local rural. El Ecomuseo de Almócita, siendo consciente de nuestros recursos naturales, culturales, y siempre dentro de un modelo de desarrollo endógeno, apuesta, por un lado, por el embellecimiento municipal y, por otro lado, por la puesta en valor de nuestro patrimonio con el apoyo del arte contemporáneo comprometido y crítico con el mundo global (arte en la calle), el desarrollo de la producción, la recuperación del paisaje y el fomento del comercio local $(\mathrm{km} \mathrm{0})$ mediante el desarrollo de espacios de colaboración y formación en agroecología.

\section{Espacios/salas: arte en la calle}

La idea que estamos desarrollando es la creación de espacios/salas en la calle, poniendo en valor nuestra arquitectura tradicional alpujarreña de vida y visibilidad cotidiana, con el apoyo del arte contemporáneo y las intervenciones artísticas comunitarias colaborativas (transitional art). Acogiendo la idea de que "el arte ha expandido su campo de acción — desde el museo y la galería - hacia la cotidianeidad (Mierle Laderman Ukeles)" (ALBELDA; PARREÑO; MARRERO, 2018) y nos sirve de apoyo-ignición para fortalecer la unión entre el proyecto municipal global de cambio y los y las vecinas par- 
tícipes, por tanto, "el papel del arte es más destacado y cumple la función de ignición, es decir, como generador de otras acciones, y pone de manifiesto la capacidad de la acción artística de actuar como precursora o desencadenante de dinámicas de cambio hacia la sostenibilidad en la sociedad" (SÁNCHEZ LEÓN, 2018)

En la creación de los espacios/salas de nuestro ecomuseo, hemos realizado intervenciones artísticas diferenciadas, pudiéndolas dividir en:

$>$ Actuaciones de coautoría guiada donde "el artista cede el protagonismo creador en favor de la coautoría, y la colaboración con expertos y/o público es intensa, siendo los temas de fondo a tratar las grandes narrativas de la transición a la sostenibilidad" (SÁNCHEZ LEÓN, 2018). Son las más abundantes y el inicio del proyecto con las obras realizadas en 2010 por los campos de trabajos internacionales en colaboración con la población vecina. Debemos destacar intervenciones como el Árbol de la Música (puesta en valor de una encina centenaria que se había secado); muralguía homenaje a la uva de embarque (puesta en valor de nuestro patrimonio tradicional y oral, con un trabajo en el proceso creativo de intercambio generacional sobre la canción de la faena y procesos productivos tradicionales con la guía de nuestras y nuestros agricultores); mural de Almócita internacional, en un muro degradado en la entrada del municipio; mural de la mariposa y la ruleta del amor (mural-juego hacia la consciencia grupal y amor por el ser humano para conocer de forma diferente los rincones del municipio).

$>$ Murales individuales de artistas, apostando por la puesta en valor de la vida tradicional como los murales homenaje a los burros, imágenes de nuestro pueblo, juegos infantiles, etc.

$>$ Grafitis, realizados durante el evento anual de arte en la calle denominado la Noche con Alma; son realizados en fachadas que el vecindario cede como espacios de lienzo comunitario. Destacamos el homenaje a Cervantes y, especialmente, el mural encargado por la Asociación de Mujeres la Fuente de los Naranjos para mejorar un muro degradado del municipio con la temática de "Almócita contra los malos tratos" en homenaje al pilar de la sociedad rural: la mujer rural.

> Exposición fotográfica "Almouseum" en homenaje a la tradición oral y el intercambio de sabiduría intergeneracional, poniendo en valor el antiguo barrio de la Judería y el alma de nuestra identidad.

> Poesías en las fachadas, con el objetivo de introducir la cultura en la visibilidad cotidiana haciendo homenaje a poetas reconocidos como Benedetti, García Lorca o Machado y cediendo un espacio a las nuevas poetas 


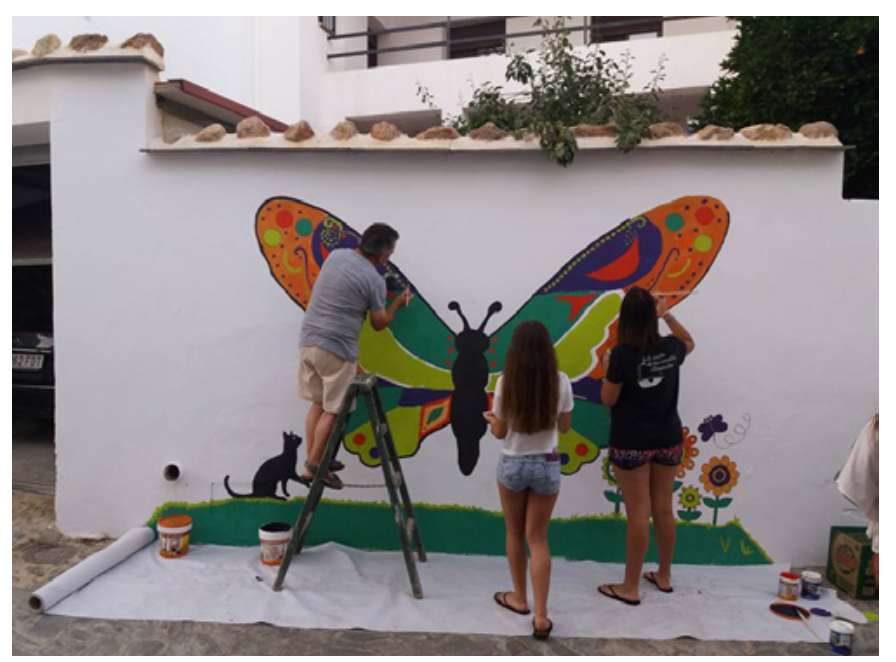

con poesías ilustradas realizadas mediante talleres de creación poética. Destacamos cómo el ente social ha adquirido el proyecto como suyo, incorporando poesías en nuestras calles de la población local. Así, algunas vecinas han puesto poesías de sus hijas o nietas en sus fachadas.

$>$ Espacio/sala del Parque de Esculturas en un antiguo basurero histórico conocido como el Laerón, recuperando el territorio cercano al municipio mediante la creación de un parque periurbano que está empezando a acoger el espacio destinado a esculturas/paisaje.

> Candil más grande del mundo (Record Guinness), realizado por el herrero artesanal local como hito de importancia para la celebración del evento de La Noche de los Candiles, escultura con contenido reivindicativo contra el uso excesivo de luz eléctrica en nuestra sociedad y para la puesta en valor de la iluminación tradicional; y que nos sirve de llamada a las visitas turísticas y posicionamiento del municipio en Internet y las redes sociales.

> Restauración del antiguo depósito, dándole un nuevo uso cultural, de recepción y como Oficina de Turismo Municipal.

Este proyecto de arte en la calle (streetarturban), de arte contemporáneo y de poesía, nos está concediendo una identidad, una imagen-marca a nivel municipal en el exterior; y nos ha servido como elemento de cohesión vecinal y de motor para otros proyectos globales en Almócita. "En conclusión, la aportación del arte en este caso hay que entenderla a nivel de conjunto más que de forma directa, como una forma de impulsar los ánimos para emprender otros proyectos alternativos y atraer a pobladores en línea con la sostenibilidad, que compensen el despoblamiento y envejecimiento" (SÁNCHEZ LEÓN, 2018). 


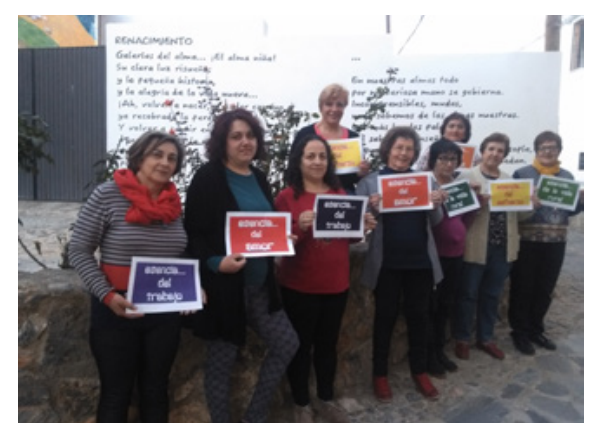

Homenaje a Mujer Rural del centro Guadalinfo | foto Sergio Pineda Iglesias

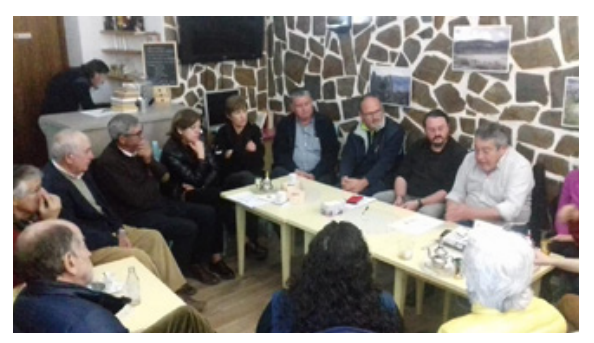

Reunión de Almocita entransicion, grupo de autosuficiencia energetica | foto Alberto Bretones Felices

\section{Programación anual cultural y reivindicativa}

Para la propuesta anual del evento partimos de la idea de "Reflexionar sobre lo que tu grupo está haciendo y celebrar lo que habéis conseguido, es una parte esencial de la transición" (HOPKINS; THOMAS, 2016). Así, la dinámica habitual del grupo -"soñar-planificar-hacer"- ha de completarse también con una importante fase de celebración que nutra a las personas emocionalmente, trabajando de forma paralela e integrada el cambio en las relaciones humanas, fomentando el uso del amor como base para enamorarnos de un proyecto, y que a su vez, favorezca el empoderamiento vecinal con el proyecto y con el "ser-alma-arete" del municipio. A continuación presentamos los cuatro eventos/celebraciones con un marcado carácter reivindicativo que desarrollamos a lo largo del año:

\section{La Noche de los Candiles}

Es una apuesta "por una nueva manera de disfrutar el turismo basándose en los rituales mágicos, precristianos y antiguos promoviendo valores como la mirada interior, la sostenibilidad, el consumo responsable y el ecoturismo" (RUIZ REAL, 2017) con un cariz reivindicativo sobre el uso excesivo de energía eléctrica en nuestra sociedad postindustrial y, además, para poner en valor el fuego/candil como elemento de iluminación histórica, consiguiendo en 2013 el titulo Record Guinnes del Candil más grande del mundo.

Pero debemos destacar la implicación de la población consiguiendo tener hasta 100 personas voluntarias en la organización. Con todo, el municipio en su totalidad no enciende ninguna luz eléctrica durante el evento (visión de iluminación histórica de nuestras calles y plazas), promoviendo con ello las iniciativas colectivas hacia la sostenibilidad, la ecología y el consumo energético responsable.

A nivel turístico la personalidad y diferenciación de este evento está basada, además de en la inusual iluminación, en los conciertos gratuitos de música medieval, folkpagan, newfolk, concursos de fachadas y fotografía sin flash, consiguiendo transformar "un destino de turismo rural estacional en uno de los destinos turísticos más conocidos y demandados de la región de la Alpujarra" (RUIZ REAL, 2017.)

\section{Ecoencuentro}

Es un encuentro formativo en ecología, agroecología y nuevos proyectos contra el cambio climático, donde además del espacio de charlas técnicas se genera un espacio de celebración en el ecomercado con artesanos y artesanas, música en la calle, venta de productos agroecológicos, etc.

Almomed, medita por los buenos tratos

El Festival de meditación por los buenos tratos Almomed está siendo la 
semilla para el cambio en las dinámicas de las relaciones sociales entre vecinos y vecinas, apostando por el desarrollo personal para mejorar las relaciones comunitarias y luchar contra una de las grandes lacras de nuestra sociedad: el maltrato de la cultura machista hacia las mujeres.

\section{La noche con Alma}

Festival de arte en la calle, germen del proyecto de ecomuseo desde 2010, introduciendo en nuestra vida cotidiana la cultura y el arte. Se realiza una programación de cultura en la calle donde tiene cabida el circo, la poesía, la pintura, la música en directo, los performance siempre con contenidos de carácter reivindicativo y con la mirada puesta en el apoyo de la sostenibilidad y la ecología.

\section{Agroecología, puesta en valor de nuestro paisaje y su tierra}

Dentro del proyecto de Ecomuseo se incorpora otro espacio/sala: el huerto del abuelo Emiliano (huerto comunitario) donde se desarrolla, principalmente, nuestra apuesta por la agroecología, definiéndola como el sistema de técnicas de producción ecológica, basadas en la sostenibilidad ambiental, el amor por la tierra y el uso de los elementos naturales de nuestro entorno, unido al estudio de preservación de la tradición agrícola alpujarreña con colaboraciones y puesta en valor de nuestros agricultores, y agricultoras, más veteranos: por tanto, se crea un nuevo agroecosistema social participativo de producción contra el cambio climático.

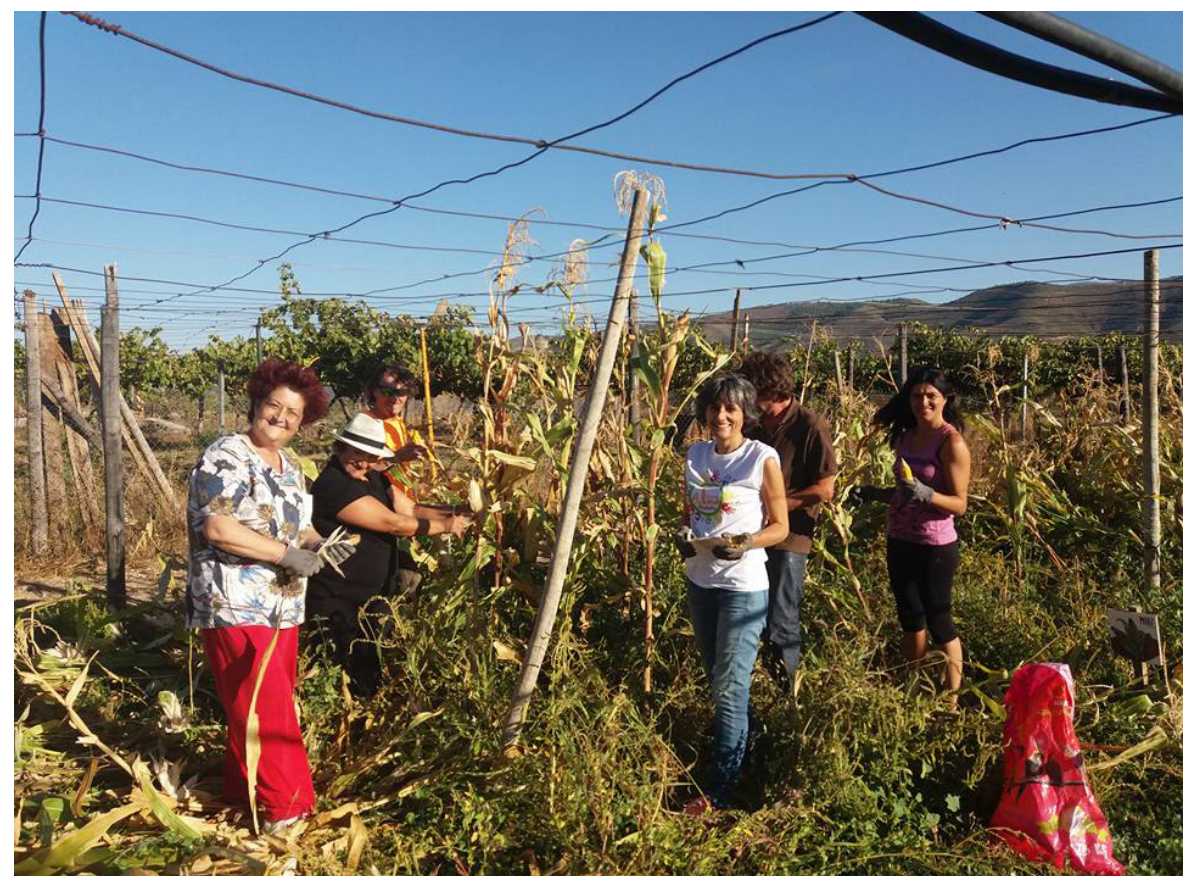


Desde Almócita en Transición se apuesta, como un pilar fundamental del desarrollo rural, por "las técnicas de agroecología como base para crear un sistema de economía circular -local- consistente en la creación de 'sistemas' socioeconómicos que contribuyan a crear comunidades resilientes y autosuficientes en la medida de lo posible" (VV. AA., 2014).

En el huerto del abuelo Emiliano desarrollamos varios proyectos pilotos participativos:

$>$ Gallinero y avicompostero comunitario, donde siete familias se están encargando de llevar sus restos orgánicos de la semana; a cambio, recogen los huevos y el compost creado. De esta forma, se ha conseguido no generar, en menos de dos años, 2,5 toneladas de basura orgánica y se ha recuperado la tradición de la gestión/reciclado de nuestra basura a cambio de alimentar a los animales. Este proyecto está siendo la base para articular un sistema de composteras municipales que se pretenden instalar a lo largo del municipio, con el objetivo final de no generar basura orgánica en toda Almócita.

$>$ Nuevas técnicas de producción que necesiten el uso de menos agua y de tierra, así se han creado bancales profundos para autoconsumo y formación.

$>$ Cursos de formación agroecológica donde se trabajan conocimientos/técnicas de producción ecológica, creación de insumos, fertilizantes sin uso de químicos, con el conocimiento de las tradicionalmente mal denominadas "malas hierbas". En este punto, me gustaría destacar el proyecto formativo de apoyo a la integración social de personas inmigrantes en colaboración con el Centro de Menores No Acompañados de nuestro pueblo vecino, Padules.

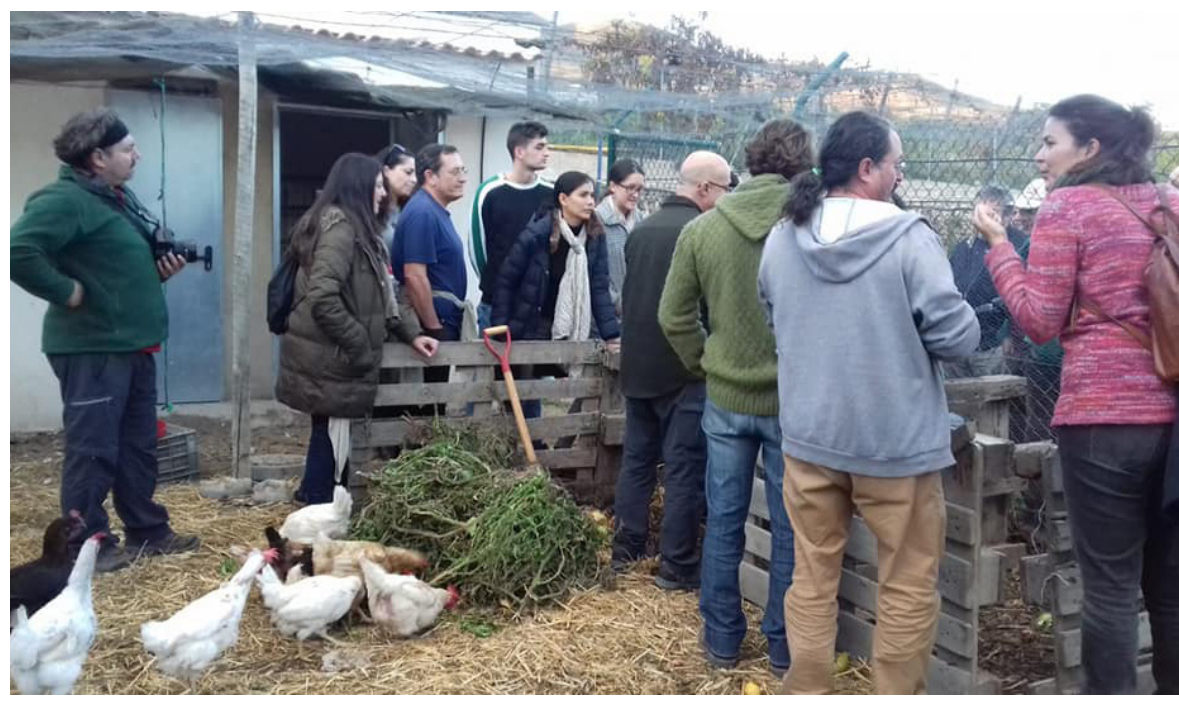



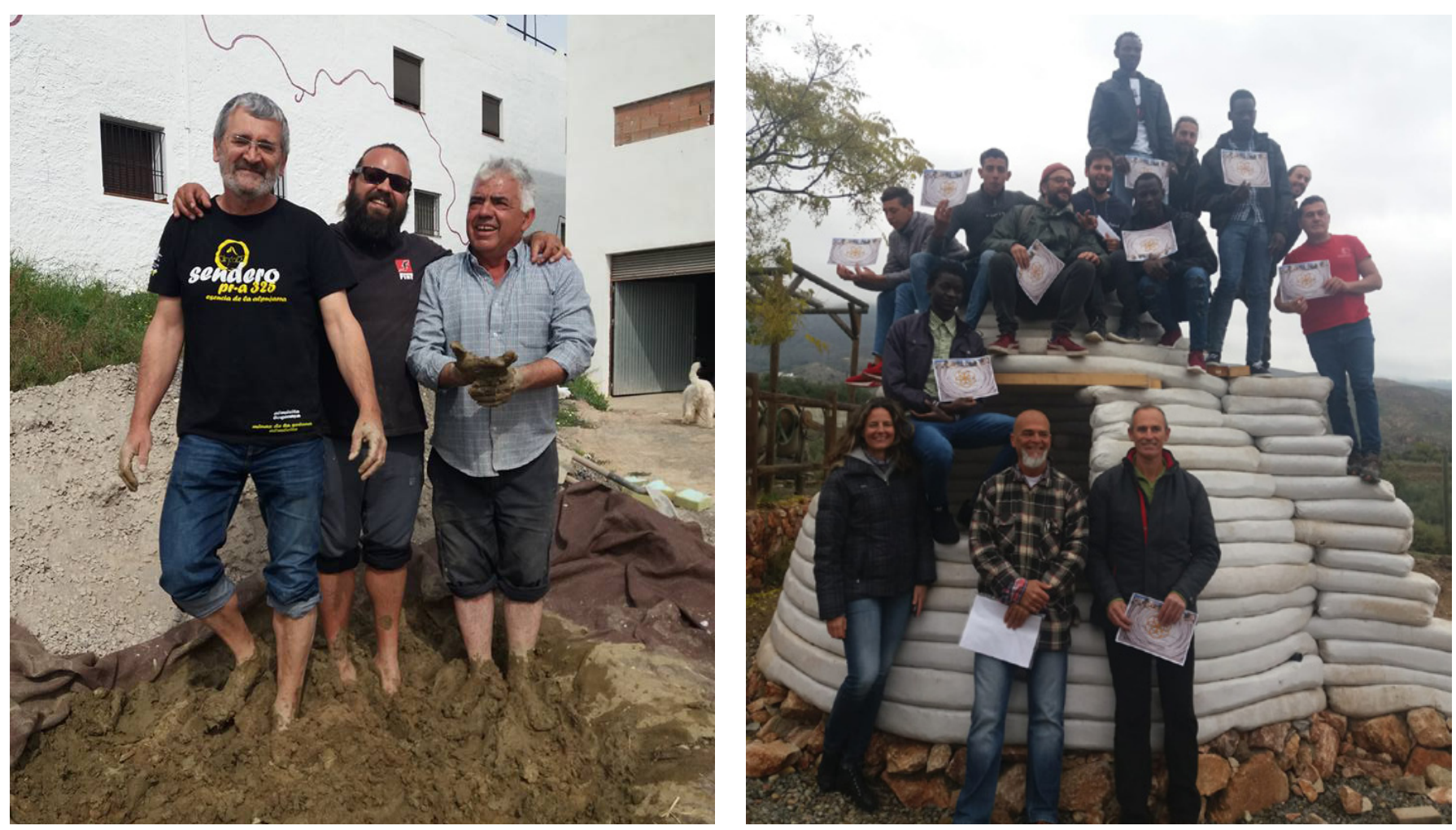

Taller de ladrillos de adobe tradicional para el futuro horno comunitario | fotos Sergio Pineda Iglesias

$>$ Espacio didáctico para colegios, visitantes y turistas, donde se les acerca al amor a la tierra y a la autosuficiencia alimentaria, contando durante 20182019 con más 1.000 asistentes, en colaboración con varias asociaciones y empresas de educación medioambiental del territorio.

Además, en paralelo, desarrollamos proyectos de bioconstrucción (domos turísticos en el camping municipal con la técnica del superadobe, talleres de adobe tradicional para un futuro horno comunitario que se ha visto abocado a su desaparición en casi todos los ámbitos rurales), creación de un banco de tierras municipal en cesión para nuevos pobladores, apoyo a dos grupos de consumo instalados en el municipio, etc.

\section{RESULTADOS Y CONCLUSIONES: EMPEZAMOS A GANAR A LA DESPOBLACIÓN}

Esta diferenciada dinámica municipal conlleva el acercamiento continuo de muchos visitantes, el afianzamiento del rol de municipio sostenible y amante de la cultura y la creación de "la marca Almócita". La identidad de nuestro municipio está identificada con la democracia participativa, el arte en la calle, la sostenibilidad y el compromiso medioambiental recibiendo varios 
premios en los últimos años de Ecologistas en Acción, Consejería de Medio Ambiente de la Junta de Andalucía y la petición de charlas en entidades como la Universidad de Córdoba, Universidad Autónoma de Madrid, congresos nacionales de agroecología (Red Terrae) o de despoblamiento, etc. y, especialmente, nos está aportando nuevos pobladores (20 neorrurales, en un municipio de 180 personas empadronadas, de las cuales, viven a diario alrededor de 110 personas), aportando a nuestro pueblo tres nuevos niños en el colegio, pasando de seis a nueve, neorrurales que aportan dos grupos de consumo agroecológicos al municipio, lo que ha conllevado que varios agricultores locales cambien su dinámica de producción hacia técnicas más sostenibles, olvidando el tratamiento de sus producciones con fitosanitarios, nuevas normativas contra el uso de fitosanitarios en los espacios municipales, aumento del interés por las nuevas fuentes de energías renovables, nuevas técnicas de bioconstrucción sostenibles y mayor empoderamiento vecinal en las líneas futuras de trabajo y puesta valor.

Almócita, su equipo municipal y nuestros vecinos y vecinas se han dado cuenta de que estos pilares están atrayendo personas, visibilidad, turismo sostenible y nuevos pobladores al municipio; valorando el proyecto global de ecomuseo como elemento fundamental para la puesta en valor de nuestros recursos diferenciadores, $y$, por tanto, conseguir la pervivencia de la memoria pasada, presente y futura consiguiendo comenzar a evitar el grave problema del despoblamiento que está arrasando el medio rural a nivel nacional. Por tanto "Almócita seguirá embelleciendo sus calles y ganando atractivo con cada festival de La Noche con Alma, cada exposición en el Almouseum o cada mural. La línea ética que desarrollan con construcciones como el domo y las que vendrán, o el proyecto de compostaje seguirá atrayendo a nuevos pobladores en consonancia. El Ecomuseo global ( aquí quiere decir que se plantea el espacio pueblo como pueblo-museo, como contenedor de arte y patrimonio en si. Y esto es un cita literal de la tesis de Nuria) que planea que acoja muchos de estos proyectos y otros nuevos (parque de esculturas, bosque mediterráneo, parque de arbustos amadrinados y otros en proceso) será un escenario demostrativo perfecto de como arte y sostenibilidad pueden impulsarse mutuamente." (SÁNCHEZ LEÓN, 2018). 


\section{BIBLIOGRAFÍA}

- AlBeldA, J.; PARREÑO, J. M.; MARRERO, J. M. (coord.) (2018) Humanidades Ambientales: Pensamientos, Arte y Relatos para el Siglo de la gran prueba. Madrid: La Catarata, 2018

- La DESPOBLACIÓN rural, un problema de Estado (2017) Red Española de Desarrollo Rural [en línea], 23 de febrero de 2017 <http://www.redr.es/es/cargarAplicacionNoticia. do?identificador=29298> [Consulta: 29/07/2019]

- GANTES, Y. (2018) La despoblación rural, un problema que tienen las ciudades. el.Economista.es [en línea], 29 de octubre de 2018 <https://www.eleconomista.es/ evasion/noticias/9483314/10/18/La-despoblacion-ruralun-problema-que-tienen-las-ciudades.html> [Consulta: 29/07/2019]

- HOPKINS, R.; THOMAS, M. (2016) The Essential Guide to Doing Transition. 1a ed. Totnes: Transition Network. Disponible en línea: <https://transitionnetwork.org/wpcontent/uploads/2016/09/The-Essential-Guide-to-DoingTransition.pdf> [Consulta: 13/09/2019]

- RUIZ REAL, J. M. (coord.) (2017) Destination Branding. A compilation of success case [en línea]. AECIT Spanish Association of Scientific Experts in Tourism. Ibrave Erasmus, $2017<$ https://www.ibraveproject.eu/files/manualfinal.pdf> [Consulta: 02/07/2019]

- SÁNCHEZ LEÓN, N. (2018) La función del arte en procesos de transición a la sostenibilidad: casos anglosajones y españoles. Tesis doctoral inédita. Universitat Politècnica de València, 2018 <doi:10.4995/ Thesis/10251/113603> [Consulta: 30/09/2019]

- VV. AA. (2014) Redpoblar. Analizando el Medio Rural en clave positiva [en línea]. sl: Red Española de Desarrollo Rural, $2014<$ <ttps://issuu.com/redr/docs/redpoblar> [Consulta: 30/09/2019] 